\title{
Journal of Limnology: of ancestors and descendants
}

In spite of the title, this is not the beginning of a long and boring family saga. I simply need to take a few minutes of your time to explain the history of this journal: where it is coming from, why it is changing and where it is going. Born in 1940 with the name of Memorie dell'Istituto italiano di Idrobiologia, the funding body at that time, the journal has been for over 50 years a non-negligible piece of limnological literature, hosting papers signed by the most important names in inland waters ecology. To mention but a few of them, Baldi, Tonolli, Hutchynson, Margalef, Edmondson, Wetzel, and Vollenweider all contributed to the Memorie with relevant and still cited articles. The Memorie, distributed only on an exchange basis, was a predecessor of sorts to open access publication for decades. It experienced a renewed diffusion with the online publication in the second half of the 90 s, becoming the first full open access journal devoted to freshwater ecology. In 1998 its name was changed in the more palatable Journal of Limnology, thus increasing its international flavor. The newborn Journal of Limnology continued the tradition of its ancestor, ensuring the peer reviews of submitted manuscripts and continuing as a freely accessible and downloadable publication. In 2010 , thanks to its growing online diffusion, it received an impact factor, despite its in-house production handled by researchers instead of a professional publisher. A few years later, in 2012, the increasing number of submissions prompted the Journal of Limnology to move towards the current publishing platform. The online handling of submissions, peer-review process, copyediting, ahead of print, and publishing allows to produce three issues per year, plus supplements. The number of citations of our journal in the last 4 years $(2012-2015)$ increased by 25 times (Web of Science, Thomson) and the Journal of Limnology reached the second place in the field as Immediacy Index (0.322, Journal Citation Report, Thomson). Its Impact Factor is now 1.725.

The journal aims to further develop, increasing its diffusion and reducing the time between submission and publishing - both for ahead of print and for online final while remaining fully open access. This can be done only thanks to the help of many colleagues Associate Editors and Referees who generously and freely accepted the challenging task of participating in the peer review process. However, the drastic decrease in research funds prevents the Institute of Ecosystem Study to fully support the publication of the Journal of Limnology. Beginning July 2016 the Authors will be required a flat-rate contribution to open access publication of their accepted manuscripts (see details in cover). I am sure this will not prevent you from publishing on the Journal of Limnology, which is and will remain a non-profit journal, made by limnologist for limnologist, and devoted to spreading quality scientific results from whatever side they come.

Looking forward to your submissions, I greet you cordially

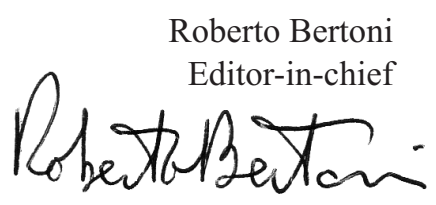

